\title{
Исследование влияния
}

\section{на динамику жизнедеятельности микроорганизмов высокочастотных электромагнитных полей, а также растворов анолитов и католитов}

\author{
Канд. хим. наук В. С. СИБИРЦЕВ ${ }^{1}$ канд. хим. наук М. А. ЧЕКАНОВ 2 ,

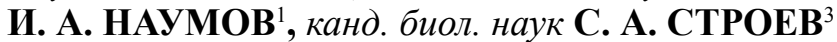 \\ ${ }^{1}$ Университет ИТМО \\ ${ }^{2}$ Институт молекулярной биологии и генетики Наџчональной академии наук Украинь \\ ${ }^{3}$ Университет Тампере, Финляндия \\ E-mail: vs1969r@mail.ru
}

\begin{abstract}
Описана методика биотестирования, предусматривающая регистрацию изменений интенсивностей упругого светорассеяния, а также светопоглощения и собственной фотофлуоресценции белковой составляющцей образцов с жизнеспособными тестовыми микроорганизмами, инкубируемых в жидкой питательной среде в присутствии и в отсутствие различных тестируемых факторов. Представлены результаты анализа с помощью данной методики влияния на динамику жизнедеятельности микрооранизмов (таких как Escherichia coli, Rhodotorula glutinis и Chlorella vulgaris) различных количеств анолита и католита (получаемых электролизом водных растворов $\mathrm{NaCl}$ и $\mathrm{Na}_{2} \mathrm{SO}_{4}$ ), а также внешних высокочастотных электромагнитных полей (ВВЭП) с разной напряженностью (U) и частотой ее изменения (v) и при разных режимах воздействия их на тестовые микроорганизмы (ТМ). На основании чего показано, что даже достаточно простая электролизная обработка водных растворов общедоступных неорганических солей может быть использована для приготовления эффективных и безопасных как антисептических (растворы анолитов), так и пробиотических (растворы католитов) средств. Слабые ВВЭП мегагерцового диапазона в зависомости от своей частоты могут значимо как ингибировать, так и активировать жизнедеятельность ТМ. Периодическое воздействие ВВЭП оказывает большее влияние на ТМ, чем постоянное. А при совместном действии ВВЭП и растворы анолитов либо католитов могут взаимоусиливать свое влияние на жизнедеятельность ТМ.
\end{abstract}

Ключевые слова: биотестирование, микроорганизмы, анолиты, католиты, электромагнитное поле.

\section{Информация о статье:}

Поступила в редакцию 23.09.2019, принята к печати 22.11.2019

DOI: $10.17586 / 1606-4313-2019-18-4-42-48$

Язык статьи - русский

Для цитирования:

Сибириев В. С., Чеканов М. А., Наумов И. А., Строев С. А. Исследование влияния на динамику жизнедеятельности микроорганизмов высокочастотных электромагнитных полей, а также растворов анолитов и католитов // Вестник Международной академии холода. 2019. № 4. С. 42-48.

\section{Influence on microorganisms'vital activity of high frequency electromagnetic fields and solutions of catolytes and anolithes}

\author{
Ph. $D$. $V$. S. SIBIRTSEV ${ }^{1}, P h$. D. M. A. CHEKANOV ${ }^{2}$ I. A. NAUMOV ${ }^{1}, P h$. $D$. S. A. STROYEV ${ }^{3}$ \\ ${ }^{1}$ ITMO University \\ ${ }^{2}$ Institute of Molecular Biology and Genetics of the National Academy of Sciences of Ukraine \\ ${ }^{3}$ University of Tampere, Finland \\ E-mail: vs1969r@mail.ru
}

A biotesting technique is described, which provides for recording changes in the intensities of elastic light scattering, as well as light absorption and intrinsic photofluorescence of the protein component of samples with viable test microorganisms incubated in a liquid nutrient medium in the presence and absence of various test factors. The results of the analysis using this technique of the influence on the dynamics of vital activity of microorganisms (such as Escherichia coli, Rhodotorula glutinis and Chlorella vulgaris) of various amounts of anolyte and catholyte (obtained by electrolysis of aqueous solutions of $\mathrm{NaCl}$ and $\mathrm{Na2SO}$ ), as well as external high-frequency electromagnetic fields (EHFEF) with different intensity (U) and frequency of its change (v) and with different modes of exposure to test microorganisms (TM), are presented. On the basis the results it has been shown that even a fairly simple electrolysis treatment of aqueous solutions of commonly available 
non-organic salts can be used to prepare effective and safe antiseptic (solutions of anolytes) and probiotic (solutions of catholytes) agents. Weak EHFEF of the megahert, range, depending on their frequency, can significantly inhibit and activate the vital activity of TM. Periodic exposure to EHFEF has a greater effect on TM than permanent one. With the combined action of EHFEF and solutions of anolytes or catholytes, they can mutually reinforce their influence on the vital activity of $T M$.

Keywords: biotesting, microorganisms, anolytes, catholytes, electromagnetic field.

\section{Article info:}

Received 23/09/2019, accepted 22/11/2019

DOI: $10.17586 / 1606-4313-2019-18-4-42-48$

Article in Russian

\section{For citation:}

Sibirtsev V. S., Chekanov M. A., Naumov I. A., Stroyev S. A. Influence on microorganisms'vital activity of high frequency electromagnetic fields and solutions of catolytes and anolithes. Vestnik Mezhdunarodnoi akademii kholoda. 2019. No 4. p. 42-48.

\section{Введение}

В последнее время, продолжает наблюдаться рост численности населения, с все большей концентрацией его в районах мегаполисов, увеличивается численность и агрессивность микрофлоры, сопровождающей человека и производимую им продукцию (особенно пищевую). Возникает необходимость увеличения количества и ассортимента производимой и потребляемой человеческим обществом пищевой и иной продукции, а также увеличение сроков ее хранения и т. п. В связи с этим, все большее значение приобретают разработка и внедрение в массовое производство методов, позволяющих проводить как можно более надежную и долгосрочную стерилизацию и консервацию пищевой и иной продукции, без значимых потерь ее потребительских свойств, а также активировать жизнедеятельность организмов, способствующих протеканию различных биотехнологических процессов, и ингибировать жизнедеятельность организмов, мешающих протеканию таких процессов.

В настоящее время для пищевой продукции наиболее распространены методы термической стерилизации и консервации [1-9]. Однако они либо существенно изменяют потребительские свойства стерилизуемой продукции (особенно в отношении биологической активности входящих в ее состав биоорганических веществ), либо весьма длительны и/или энергозатратны (как в случае применения методов дробной стерилизации, кратковременной высокотемпературной обработки, глубокой заморозки, лиофильной сушки и т. п.). Методы микробиологической и биохимической консервации (такие как сквашивание, сбраживание, соление, добавление к консервируемой продукции сахаров, спиртов, жиров, органических кислот и т. п.) [5-9] как правило в еще большей мере, чем термическая обработка меняют потребительские свойства консервируемой продукции. А копчение или добавление синтетических химических консервирующих агентов значительно усиливают антибиотические свойства обрабатываемой продукции [7-10].

Альтернативой этому может быть добавление к стерилизуемой продукции химических агентов, обладающих ярковыраженной, но краткосрочной антибиотической активностью (как в случае, например, свежеприготовленных водных растворов анолитов, содержащих в большом количестве и разнообразии ионы, радикалы и иные неустойчивые химически активные частицы, образую- щиеся в процессе электролиза), либо воздействие на стерилизуемую продукцию внешними высокочастотными электромагнитными полями (ВВЭП) с последующей герметичной упаковкой продукции.

Таким образом, разработка способов стерилизации и консервации пищевой и иной продукции, а также воздействия на различные биотехнологические процессы ВВЭП, либо растворов анолитов или католитов является в настоящее время весьма актуальной задачей.

Однако принятые в настоящее время в качестве стандартных при микробиологическом тестировании процедуры оценки общей выживаемости микроорганизмов [11-17] дают, как правило, лишь весьма неполную и субъективную информацию о летальных нарушениях жизнедеятельности тестовых организмов.

В связи с чем, целью данной работы стало исследование влияния вышеупомянутых растворов анолитов и католитов, а также ВВЭП с различными параметрами, при разных дозах и режимах введения их в тестовые системы (ТC) на динамику жизнедеятельности различных тестовых микроорганизмов (ТМ), представляющих собой модель микрофлоры, ингибировать или активировать жизнедеятельность которой необходимо при стерилизации различной продукции либо управлении биотехнологическими процессами.

\section{Материалы и методы}

В связи с вышесказанным, исходя из результатов уже имевшихся многолетних авторских наработок по различным способам инструментального биотестирования [18-36], в настоящей работе для проведения сравнительного анализа влияния на динамику жизнедеятельности различных микроорганизмов слабых мегагерцовых электромагнитных полей, а также разных концентраций свежеприготовленных водных растворов католита и анолита применялась следующая специально разработанная методика комплексного, инструментального микробиологического тестирования.

Для каждой совокупности тестируемых факторов (ТФ) проводилось по четыре серии измерений, перед началом каждой из которых готовилась питательная среда (ПС), представлявшая собой стерильный водный раствор с $\mathrm{pH} 7,2 \pm 0,2$, содержащий 20 г/л сахарозы, 3 г/л $\mathrm{NH}_{4} \mathrm{NO}_{3}$, 1 г/л $\mathrm{KH}_{2} \mathrm{PO}_{4}, 1$ г/л $\mathrm{NaH}_{2} \mathrm{PO}_{4}, 1$ г/л $\left(\mathrm{NH}_{4}\right)_{2} \mathrm{~S}, 0,2$ г/л $\mathrm{Mg}$ $\left(\mathrm{NO}_{3}\right)_{2}, 0,06$ г/л $\mathrm{FeCl}_{3}$ и 0,02 г/л $\mathrm{CaCl}_{2}$. Затем ПС засева- 
лась Escherichia coli ATCC 25922, Rhodotorula glutinis АТCC 10659 или Chlorella vulgaris АТСС 9765 (выбранных в качестве тестовых биообъектов, т. к. они являются типичными представителями широко распространенных в естественных условиях видов микроорганизмов, принадлежащих к разным таксономическим группам и используемых в различных биотехнологических процессах) и инкубировалась при температуре $30 \pm 0,1{ }^{\circ} \mathrm{C}$, пока содержание жизнеспособных микроорганизмов в ней не достигало примерно $5 \times 10^{6}$ кл/мл (что удостоверялось нефелометрическим способом по стандарту мутности).

Далее, полученная ТС разливалась по измерительным емкостям (ИЕ), в каждую из которых (за исключением 3-х контрольных) либо предварительно добавлялось (по три ИЕ в параллель) необходимое количество тестируемого объекта (TO, в качестве которого в описываемом исследовании выступали разные концентрации свежеприготовленных водных растворов католита или анолита), либо упомянутые тестовые ИЕ подвергались различным образом воздействию однородного ВВЭП с разными напряженностью $(U)$ и частотой ее изменения $(v)$. Затем как тестовые, так и контрольные ИЕ инкубировались при температуре $30 \pm 0,1^{\circ} \mathrm{C}$ в течение 9 ч. При этом у ТC, содержащихся в каждой из ИЕ, последовательно, с интервалом 3 ч, с помощью спектрофлуориметра «СM 2203» (Беларусь) регистрировались интенсивность упругого светорассеяния при 520 нм $\left(I_{o d}\right)$, оптическая плотность при 330 нм $\left(\mathrm{A}_{\mathrm{p}}\right)$ и интенсивность фотофлуоресценции при длинах волн возбуждения и эмиссии 375 и 685 нм (для C. vulgaris) либо 375 и 465 нм (для E. coli) $\left(I_{\mathrm{p}}\right)$.

После чего общая степень активирования либо ингибирования (+/ - ) ТФ жизнедеятельности ТМ рассчитывалась по формулам:

$\varepsilon_{S, k}=\left(\varepsilon_{I o d, k}+0,7 \varepsilon_{A p, k}+0,7 \varepsilon_{I p, k}\right) / 2,4$ — для E. coli и C. vulgaris; либо $\varepsilon_{S, k}=\left(\varepsilon_{\text {Iod, } k}+\varepsilon_{A \mathrm{p}, k}\right) / 2$ - для R. glutinis.

Поскольку клеточная стенка дрожжей эффективно тушила их собственную белковую фотолюминесценцию), где $\varepsilon_{I o d, k}, \varepsilon_{A p, k}$ и $\varepsilon_{I p, k}$ определялись отдельно по результатам измерений $I_{o d}, \mathrm{~A}_{\mathrm{p}}$ и $I_{\mathrm{p}}$ У ТС в ИЕ в ходе инкубации этих ИЕ по формуле

$$
\varepsilon_{i, k}=100 \times\left(\Delta Y t_{i, k}-\Delta Y c_{i, k}\right) / \Delta Y c_{i, k},
$$

где $\Delta Y t_{i, k}$ и $\Delta Y c_{i, k}$ - усредненные по выборке из $N$ ИЕ с одинаковыми уровнями ТФ (в нашем случае $N=3 \times 4=12$ ) изменения значений $i$-параметра ТС (где $i=I_{\text {od }}, \mathrm{A}_{\mathrm{p}}$ или $I_{\mathrm{p}}$ ), произошедшие за $k$ часов от начала инкубирования этой $\mathrm{TC}$ в присутствии заданного уровня ТФ $(\Delta Y t$, наблюдаемое в тестовых ИЕ) либо в его отсутствие ( $\Delta Y c$, наблюдаемое в контрольных ИЕ).

При этом растворы католита и анолита получались 30 мин обработкой 1 об.\% водных растворов $\mathrm{NaCl}$ (в прикатодном пространстве) и $\mathrm{Na}_{2} \mathrm{SO}_{4}$ (в прианодном пространстве) при силе тока 7 А и напряжении 28 В в электролизере специальной конструкции, который представлял собой параллелепипед из оргстекла, разделенный пополам полимерной ион-селективной перегородкой (допускающей ионную электропроводность - но не позволяющей количественно смешиваться приэлектродным растворам), с электродами, выполненными в виде метал- лических пластин (анод — платинированный; катод из нержавеющей стали), целиком занимающих две длинные стороны электролизера.

А для обработки ВВЭП ИЕ (представляющие собой цилиндрические пробирки диаметром 20 мм) размещались между двумя параллельными алюминиевыми пластинами, расположенными друг от друга на расстоянии 20 либо 50 мм и подключенными к выходу «0,1-1V» одного из генераторов «Г4-18А», установленных в режим непрерывной генерации с несущей частотой $35,9,3$, 0,6 либо 0,1 МГц и выходным напряжением 1 В. При этом применялось три вида обработки: 1 - тестовые ИЕ подвергались постоянному воздействию ВВЭП с разными $U$ и $v ; 2$ - после 30 мин воздействия на тестовые ИЕ ВВЭП на следующие 30 мин оно отключалось, после чего снова включалось на 30 мин и т. д. (режим переменного воздействия ВВЭП); 3 -в тестовые ИЕ предварительно добавлялся раствор католита или анолита в заданной концентрации, после чего они подвергались переменному воздействию ВВЭП.

\section{Результаты и обсуждение}

Наиболее интересные данные $\varepsilon_{S, k}$, определявшиеся через 3, 6 и 9 ч инкубирования разных представителей природной микрофлоры [12-14] в присутствии разных количеств свежеприготовленных водных растворов анолита $(A n)$ и католита $(K t)$, а также при разных режимах воздействия на них однородного внешнего электрического поля (ВВЭП) с разными напряженностью (U) и частотой ее изменения (v)., полученные описанным выше способом, представлены в табл. 1.

Номера ТФ соответствуют: $1-5$ - добавлению в тестовые ИЕ $A n$ и $K t$ в разных концентрациях: 1 об.\% $A n(1)$, 5 об.\% An (2), 5 об.\% Kt (3), 10 об.\% Kt (4), 25 об.\% Kt (5); 6-11 - постоянному воздействию на тестовые ИЕ ВВЭП с разными $U$ и $v: U=20 \mathrm{~B} /$ м и $v=0,1 \mathrm{MГц} \mathrm{(6),} U=20 \mathrm{~B} / \mathrm{м}$ и $v=3$ МГц (7), $U=20 \mathrm{~B} / \mathrm{M} \mathrm{и} v=35$ МГц (8), $U=50 \mathrm{~B} / \mathrm{м} \mathrm{и} v$ $=0,1 \mathrm{MГц} \mathrm{(9),} U=50$ В/м и $v=3$ МГц (10), $U=50 \mathrm{~B} / \mathrm{m}$ и $v$ $=35$ МГц (11); 12-16 - переменному воздействию на тестовые ИЕ ВВЭП с $U=50$ В/м и разными $v: v=0,1$ МГц (12), $v=0,6$ МГц (13), $v=3$ МГц (14), $v=9$ МГц (15), $v=35$ МГц (16); 17-18 - переменному воздействию на тестовые ИЕ ВВЭП с $U=50$ В/м и разными $v$ в присутствии разных концентраций $A n$ и Kt: $v=0,1$ МГц и 1 об.\% An (17), $v=35$ МГц и 5 об.\% Kt (18). Методику определения общих степеней активирования либо ингибирования (+/ - ) жизнедеятельности ТМ разными уровнями ТФ $\left(\varepsilon_{S, k}\right.$, где $k=$ 3,6 и 9 ч инкубирования), а также состав ТС, в которой инкубировались ТМ, способ приготовления $A n$ и $K t$ и способы воздействия ВВЭП на тестовые ИЕ см. в разделе «Материалы и методы». Относительная ошибка определения $\varepsilon_{\mathrm{S}}(\xi \varepsilon)$ для всех, указанных в табл. 1, значений находилась в диапазоне от 10 до $20 \%$.

Исходя из данных табл. 1, можно сделать следующие выводы.

Наибольшая, среди использованных ТМ, чувствительность к исследо-ванным в данной работе ТФ (таким как разные количества свежеприготов-ленных растворов анолитов и католитов, а также ВВЭП с разными $U$ и $v$, а также режимами воздействия на ТМ), как правило, была характерна для C. vulgaris, а наименьшая — для E. coli. 
Общая степень $\varepsilon_{S, k}$, определяемая через 3, 6 и 9 ч инкубирования

Total degree $\varepsilon_{S, k}$ determined after 3,6 and $9 \mathrm{~h}$ incubation

Table 1

\begin{tabular}{|c|c|c|c|c|c|c|c|c|c|c|c|c|c|c|c|c|c|c|}
\hline$T \Phi$ & 1 & 2 & 3 & 4 & 5 & 6 & 7 & 8 & 9 & 10 & 11 & 12 & 13 & 14 & 15 & 16 & 17 & 18 \\
\hline E. coli $\varepsilon_{S, 3} \%$ & -55 & -98 & 41 & 84 & 141 & -25 & -15 & 12 & -49 & -33 & 28 & -63 & -43 & -36 & 10 & 39 & -98 & 125 \\
\hline E. coli $\varepsilon_{S, 6} \%$ & -43 & -95 & 33 & 71 & 103 & -28 & -18 & 14 & -57 & -38 & 32 & -72 & -50 & -43 & 11 & 46 & -92 & 93 \\
\hline E. coli $\varepsilon_{S, 9}, \%$ & -20 & -90 & 23 & 51 & 87 & -15 & $-9,3$ & 7,2 & -30 & -20 & 17 & -43 & -32 & -29 & 6 & 25 & -86 & 71 \\
\hline R. glutinis $\varepsilon_{S, 9} \%$ & -26 & -95 & 30 & 66 & 103 & -20 & -12 & 9,4 & -39 & -26 & 22 & -56 & -42 & -38 & 8 & 33 & -93 & 154 \\
\hline C. vulgaris $\varepsilon_{S, 9}, \%$ & -33 & -98 & 38 & 84 & 134 & -25 & -15 & 12 & -50 & -33 & 28 & -71 & -53 & -48 & 10 & 41 & -99 & 189 \\
\hline
\end{tabular}

Краткосрочная биотическая активность ТФ в отношении ТМ (характеризуемая величиной $\varepsilon_{S, 3}$, определяемой через 3 ч инкубации ТС с ТМ в присутствии ТФ) во всех случаях была значимо больше долгострочной биотической активности те же ТФ в отношении те же ТМ (характеризуемой величиной $\varepsilon_{S, 9}$, определяемой через 9 ч инкубации ТС с ТМ в присутствии ТФ). В то время как среднесрочная биотическая активность (характеризуемая величиной $\varepsilon_{S, 6}$, определяемой через 6 ч инкубации ТС с ТМ в присутствии ТФ) у растворов анолитов и католитов во всех случаях была больше их долгосрочной, но меньше краткосрочной биотической активности. При том, что среднесрочная биотическая активность ВВЭП превышала как долгосрочную, так и краткосрочную биотическую активность те же ВВЭП в отношении те же ТМ.

Это имело место, очевидно вследствие того, что в ходе инкубации увеличивалось количество жизнеспособных клеток ТМ, приходящихся на единичную концентрацию раствора католита или анолита. Плюс, в дополнение к этому, существенно снижалась с течением времени и сама по себе биологическая активность упомянутых растворов (содержащих весьма химически активные, но вследствие того, нестабильные химические частицы). В то время как в случае ВВЭП степень воздействия последних на ТМ существенно меньше зависела от количества жизнеспособных клеток ТМ, содержащихся в тестовых ИЕ, И тут уже значимую роль начинали играть процессы адаптации ТМ к внешним воздействиям.

Свежеприготовленный раствор анолита уже в концентрации 1 об.\% значимо ингибировал жизнедеятельность ТМ, а в концентрации 5 об.\% почти полностью ее прекращал. В то время как свежеприготовленный раствор католита, начиная с концентрации 5 об.\%, существенно активировал жизнедеятельность ТМ. И степень этой активации с увеличением концентрации католита в ТС увеличивалась.

При воздействии ВВЭП с $v$ от 0,1 до 3 МГц наблюдалось значимое ингибирование жизнедеятельности ТМ (усиливающееся с уменьшением v), а при воздействии ВВЭП с $\boldsymbol{v}$ от 9 до 35 МГц наблюдалось значимое активирование жизнедеятельности ТМ (усиливающееся с увеличением v). При этом влияние ВВЭП на ТМ усиливалось с увеличением $U$ этого поля от 20 до $50 \mathrm{~B} / \mathrm{M}$, а также изменения режима действия ВВЭП с постоянного на переменный. А ВВЭП с $v=0,1$ МГц и 1 об.\% раствор анолита либо ВВЭП с $v=35$ МГц и 5 об.\% раствор католита взаимоусиливали свое влияние на жизнедеятельность ТМ (ингибирующее в 1-м случае и активирующее во 2-м).

\section{Заключение}

Таким образом можно видеть, что с помощью представленной в настоящей работе методики биотестирования можно существенно более экспрессно, объективно и информативно, чем при использовании стандартных визуальных методов микробиотестирования, оценивать влияние на динамику жизненной активности разных микроорганизмов физико-химических факторов, даже весьма сложных по своему составу, свойствам и динамике изменения оных. Кроме того, представленная методика, по сравнению со стандартными методами, существенно менее материалоемка и трудоемка, а также представляет гораздо больше возможностей для автоматизации процесса анализа.

Помимо этого, в результате применения описанной методики мы убедились, что даже достаточно простая электролизная обработка водных растворов общедоступных неорганических солей (таких как $\mathrm{NaCl}, \mathrm{Na}_{2} \mathrm{SO}_{4}$ и т. п.) может быть использована для приготовления дешевых, эффективных, безопасных (вследствие быстрого самопроизвольного снижения с течением времени их химической и биологической активности) и, вследствие того, пригодных для массового применения как антисептических, так и пробиотических средств, которые могут быть использованы как для стерилизации пищевой продукции, так и для повышения ее биологической активности, а также для ингибирования развития посторонней микрофлоры (с помощью растворов анолитов) либо активирования развития организмов, способствующих протеканию различных биотехнологических процессов (с помощью растворов католитов).

Аналогичным образом могут быть использованы и внешние высокочастотные электромагнитные поля (ВВЭП). Так например ВВЭП с напряженностью $U=50$ В/м и частотой ее изменения $v=0,1$ МГц существенно ингибировало жизнедеятельность тестовых микроорганизмов (ТМ); а ВВЭП с $U=50$ В/м и $v=35$ МГц, наоборот, активировало жизнедеятельность ТМ. Причем, при периодическом действии ВВЭП их влияние на ТМ было большим, чем при постоянном. А ВВЭП с $v=0,1$ МГц и 1 об.\% раствор анолита, либо ВВЭП с $v=35$ МГц и 5 об.\% раствор католита взаимоусиливали свое влияние на жизнедеятельность ТМ.

Таким образом, в ходе выполнения данной работы мы нашли ряд достаточно эффективных, экономически выгодных, безопасных и доступных для широкого применения способов воздействия на жизненную активность микроорганизмов, без значимых потерь потребительских свойств стерилизуемой пищевой и иной продукции, либо активируемых биотехнологических процессов — что, как уже говорилось во введении, является весьма актуальной задачей настоящего времени. 
В дальнейшем эти исследования могут быть продолжены в различных направлениях, включая:

— нахождение способов получения более эффективных католитов и анолитов;

- нахождение более эффективных параметров ВВЭП и режимов воздействия ими на ТМ;

\section{Литература}

1. Мармузова Л. В. Основы микробиологии, санитарии и гигиены в пищевой промышленности. 8 изд. стер. - М.: Академия, 2014. 160. с.

2. Гальнкин В. А., Заикина Н. А., Потехина Т. С., Афиногенов T. E., Афиногенова А. Г. Дезинфекция и антисептика в промышленности и медицине. - СПб: Фолиант, $2004.96 \mathrm{c}$.

3. Гальикин В. А., Заикина Н. А., Кариев В. В., Шевелева С. А., Белова Л. В. Микробиологические основы ХАССП при производстве пищевых продуктов. - СПб: Проспект Науки. 2007. $288 \mathrm{c}$.

4. Бабарин В. П. Стерилизация консервов. - М.: Гиорд. 2006. $312 \mathrm{c}$.

5. Донченко Л. В., Надыкта В. Д. Безопасность пищевой продукции. 2-е изд., перераб. и доп. - М.: ДеЛи принт, 2007. 536 с.

6. Позняковский В. М. Гигиенические основы питания, качество и безопасность пищевых продуктов: учебник, 5-е изд., испр. и доп. - Новосибирск: Сиб. универ. изд-во, 2007. $455 \mathrm{c}$.

7. Зонин В. Г. Современная технология мясных консервированных продуктов. - М.: Профессия, 2008.

8. Долганова Н. В., Вершинина Е. В., Хасанова Э. К. Микробиология рыбы и рыбных продуктов. - СПб.: Лань, 2012.

9. Ким И. Н., Кушнирук А. А., Ким Г. Н. Пищевая безопасность водных биологических ресурсов и продуктов их переработки. -СПб.: Лань. 2017.

10. Люк Э., Ягер М. Консерванты в пищевой промышленности. - М.: Гиорд, 2003

11. Zvarich V. I., Stasevich M. V., Stan'ko O. V., KomarovskayaPorokhnyavets E. Z., Poroikov V. V., Rudik A. V., Lagunin A. A., Vovk M. V., Novikov V. P. Computerized prediction, synthesis, and antimicrobial activity of new amino-acid derivatives of 2-chloro-n- (9,10-dioxo-9,10-dihydro-anthracen-1-yl) acetamide. // Pharmaceutical Chemistry Journal. 2015. V. 48. Is. 9. P. 582-586. doi: 0.1007/s11094-014-1154-Z

12. Grigor'eva M. N., Stel'makh S. A., Astakhova S. A., Tsenter I. M., Bazaron L. U., Batoev V. B., Mognonov D. M. Synthesis of polyalkylguanidine hydrochloride copolymers and their antibacterial activity against conditionally pathogenic microorganisms Bacillus cereus and Escherichia coli. // Pharmaceutical Chemistry Journal. 2015. V. 49. Is. 2. P. 99-103. doi: 10.1007/ s11094-015-1230-z

13. Syniugin A. R., Ostrynska O. V., Chekanov M. O., Volynets G. P., Starosyla S. A., Bdzhola V. G., Yarmoluk S. M. Design, synthesis and evaluation of 3-quinoline carboxylic acids as new inhibitors of protein kinase CK2. // Journal of Enzyme Inhibition and Medicinal Chemistry. 2016. V. 31. № 4. P. 160-169.

14. Zhuravlev O. E., Voronchikhina L. I. Synthesis and antimicrobial activity of n-decylpyridinium salts with inorganic anions. // Pharmaceutical Chemistry Journal. 2018. V. 52. Is. 4. P. 312-315.

15. Arutyunyan G. L., Arutyunyan A. D., Gevorkyan K. A., Gasparyan S. P., Paronikyan R. V., Stepanyan G. M., Minasyan N. S.
— нахождение эффективных сочетаний ВВЭП с растворами католитов и анолитов;

- нахождение других физико-химических способов эффективного, экономически выгодного и безопасного воздействия на микрофлору при стерилизации или консервации пищевой продукции, либо управлении различными биотехнологическими процессами и т. п.

\section{References}

1. Marmuzova L. V. Fundamentals of microbiology, sanitation and hygiene in the food industry. 8 Izd. Moscow: Academy. 2014. 160 p. (in Russian)

2. Galynkin V. A., Zaikina N. A., Potekhina T. S., Afinogenov T. E., Afinogenova A. G. Disinfection and antiseptics in industry and medicine. Saint-Petersburg: Foliant. 2004. 96 p. (in Russian)

3. Galynkin V. A., Zaikina N. A., Kartsev V. V., Sheveleva S. A., Belova L. V. Microbiological basis of HACCP in food production. -Saint-Petersburg: Prospect Nauki. 2007. 288 p. (in Russian)

4. Babarin V. P. Sterilization of canned food. Moscow: Giord. 2006. 312 p. (in Russian)

5. Donchenko L. V., Nadykta V. D. Food Safety. Moscow: DeLi print, 2007. 536 p. (in Russian)

6. Poznyakovsky V. M. Hygienic fundamentals of nutrition, quality and food safety: tutorial. Novosibirsk: Siberian university. publishing house. 2007. 455 p. (in Russian)

7. Zonin V. G. Modern technology of canned meat products. Moscow: Profession. 2008. (in Russian)

8. Dolganova N. V., Vershinina E. V., Khasanova E. K. Microbiology of fish and fish products. Saint-Petersburg: Lan'. 2012. (in Russian)

9. Kim I. N., Kushniruk A. A., Kim G. N. Food safety of aquatic biological resources and products of their processing. -SaintPetersburg: Lan'. 2017. (in Russian)

10. Luke E., Jager M. Preservatives in the food industry. Moscow: Giord. 2003. (in Russian)

11. Zvarich V. I., Stasevich M. V., Stan'ko O. V., KomarovskayaPorokhnyavets E. Z., Poroikov V. V., Rudik A. V., Lagunin A. A., Vovk M. V., Novikov V. P. Computerized prediction, synthesis, and antimicrobial activity of new amino-acid derivatives of 2-chloro-n- (9,10-dioxo-9,10-dihydro-anthracen-1-yl) acetamide. Pharmaceutical Chemistry Journal. 2015. V. 48. Is. 9. P. 582586. doi: 0.1007/s11094-014-1154-z

12. Grigor'eva M. N., Stel'makh S. A., Astakhova S. A., Tsenter I. M., Bazaron L. U., Batoev V. B., Mognonov D. M. Synthesis of polyalkylguanidine hydrochloride copolymers and their antibacterial activity against conditionally pathogenic microorganisms Bacillus cereus and Escherichia coli. Pharmaceutical Chemistry Journal. 2015. V. 49. Is. 2. P. 99-103. doi: 10.1007/ s11094-015-1230-z

13. Syniugin A. R., OstrynskaO. V., ChekanovM. O., Volynets G. P., Starosyla S. A., Bdzhola V. G., Yarmoluk S. M. Design, synthesis and evaluation of 3-quinoline carboxylic acids as new inhibitors of protein kinase CK2. Journal of Enzyme Inhibition and Medicinal Chemistry. 2016. V. 31. № 4. P. 160-169.

14. Zhuravlev O. E., Voronchikhina L. I. Synthesis and antimicrobial activity of n-decylpyridinium salts with inorganic anions. // Pharmaceutical Chemistry Journal. 2018. V. 52. Is. 4. P. 312-315.

15. Arutyunyan G. L., Arutyunyan A. D., Gevorkyan K. A., Gasparyan S. P., Paronikyan R. V., Stepanyan G. M., Minasyan N. S. 
Synthesis and conversions of polyhedral compounds. 32. Synthesis and antibacterial activity of azaadamantane-containing azomethine dihydrochlorides. // Pharmaceutical Chemistry Journal. 2018. V. 52. Is. 5. P. 419-423.

16. Luzhnova S. A., Tyrkov A. G., Gabitova N. M., Yurtaeva E. A. Synthesis and antimicrobial activity of 5- (arylmethylidene) 2,4,6-pyrimidine-2,4,6 $(1 H, 3 H, 5 H)$ - triones. // Pharmaceutical Chemistry Journal. 2018. V. 52. Is. 6. P. 506-509.

17. Koshchienko Yu. V., Drobin Yu. D., Zubenko A. A., Timoshevskii D. A., Fetisov L. N., Bodryakov A. N. Synthesis and antimicrobial, antiprotozoal, and fungistatic activity of [5- (amino-, acylamino-, and 2-pyridylmethylamino) - 1-alkylbenzimidazol-2-yl] diphenylmethanols. // Pharmaceutical Chemistry Journal. 2018. V. 52. Is. 8. P. 711-715.

18. Sibirtsev V. S., Garabadzhiu A. V., Ivanov S. D. Mechanisms of variation in fluorescent properties of bis-benzimidazole dyes. // Russian Journal of Bioorganic Chemistry. 1995. V. 21. № 9. P. 633-637.

19. Ivanov S. D., Korytova L. I., Yamshanov V. A., Ilyn N. V., Sibirtsev $V$. S. Leukopenia prognosis by radiation therapy of patients with Hodgkin's disease. // Journal of Experimental and Clinical Cancer Research. 1997. V. 16. No 2. P. 183-188.

20. Ivanov S. D., Korytova L. I., Yamshanov V. A., Ilyn N. V., Sibirtsev $V$. S. Leukopenia prognosis during radiation therapy in patients with Hodgkin's disease. // Journal of Experimental and Clinical Cancer Research.. 1997. V. 16. No 4. P. 413-418.

21. Sibirtsev V. S., Garabadzhiu A. V., Ivanov S. D. Spectral properties of bisbenzimidazole dyes upon interaction with DNA. // Russian Journal of Bioorganic Chemistry. 1997. V. 23. No 12. P. 857-866.

22. Sibirtsev V. S., Glibin E. N., Ivanov S. D. Variation of spectral properties of actinocin derivatives due to equilibrium transformations. // Russian Journal of Organic Chemistry. 2000. V. 36. No 12. P. 1812-1818.

23. Sibirtsev V. S., Garabadzhiu A. V., Ivanov S. D. Comparative study of DNA-specific dyes of the indole and benzimidazole series. // Russian Journal of Bioorganic Chemistry. 2001. V. 27. No 1. P. 57-65. doi: 10.1023/A:1009535320077

24. Sibirtsev V. S., Tolmachev A. Yu., Suslov V. V., Garabadzhiu A. V., Traven' $V$. F. Dependence of fluorescence properties of compounds from psoralen, angelicin, and carbazole series on the character of their terminal substituents. // Russian Journal of Organic Chemistry. 2003. V. 39. No 6. P. 881-889. doi: 10.1023/B: RUJO. $0000003169.96393 .1 \mathrm{~d}$

25. Sibirtsev V. S. Study of applicability of the bifunctional system "Ethidium bromide + Hoechst-33258" for DNA analysis. // Biochemistry (Moscow). 2005. V. 70. No 4. P. 449-457. doi: 10.1007/ s10541-005-0136-x

26. Sibirtsev V. S., Tolmachev A. Yu., Kovaleva M. V., Garabadzhiu $A$. V., Traven $V$. F. Spectral study of interactions of 4,8,4' - trimethylpsoralen and 4,4' - dimethylangelicin dyes with DNA. // Biochemistry. 2005. V. 70. No 7. P. 822-832. doi: 10.1007/s10541-005-0190-4

27. Sibirtsev V. S. Fluorescent DNA probes: study of mechanisms of changes in spectral properties and features of practical application. // Biochemistry. 2007. V. 72. No 8. P. 887-900. doi: 10.1134/S0006297907080111

28. Sibirtsev V. S., Naumov I. A., Kuprina E. E., Olekhnov$i c h R$. $O$. Use of impedance biotesting to assess the actions of pharmaceutical compounds on the growth of microorganisms. // Pharmaceutical Chemistry Journal. 2016. V. 50. Is. 7. P. 481-485. doi: 10.1007/s11094-016-1473-3
Synthesis and conversions of polyhedral compounds. 32. Synthesis and antibacterial activity of azaadamantane-containing azomethine dihydrochlorides. Pharmaceutical Chemistry Journal. 2018. V. 52. Is. 5. P. 419-423.

16. Luzhnova S. A., Tyrkov A. G., Gabitova N. M., Yurtaeva E. A. Synthesis and antimicrobial activity of 5- (arylmethylidene) 2,4,6-pyrimidine-2,4,6 $(1 H, 3 H, 5 H)$ - triones. Pharmaceutical Chemistry Journal. 2018. V. 52. Is. 6. P. 506-509.

17. Koshchienko Yu. V., Drobin Yu. D., Zubenko A. A., Timoshevskii D. A., Fetisov L. N., Bodryakov A. N. Synthesis and antimicrobial, antiprotozoal, and fungistatic activity of [5(amino-, acylamino-, and 2-pyridylmethylamino) - 1-alkylbenzimidazol-2-yl] diphenylmethanols. Pharmaceutical Chemistry Journal. 2018. V. 52. Is. 8. P. 711-715.

18. Sibirtsev V. S., Garabadzhiu A. V., Ivanov S. D. Mechanisms of variation in fluorescent properties of bis-benzimidazole dyes. Russian Journal of Bioorganic Chemistry. 1995. V. 21. No 9. P. 633-637.

19. Ivanov S. D., Korytova L. I., Yamshanov V. A., Ilyn N. V., Sibirtsev V. S. Leukopenia prognosis by radiation therapy of patients with Hodgkin's disease. Journal of Experimental and Clinical Cancer Research. 1997. V. 16. No 2. P. 183-188.

20. Ivanov S. D., Korytova L. I., Yamshanov V. A., Ilyn N. V., Sibirtsev V. S. Leukopenia prognosis during radiation therapy in patients with Hodgkin's disease. Journal of Experimental and Clinical Cancer Research. 1997. V. 16. No 4. P. 413-418.

21. Sibirtsev V. S., Garabadzhiu A. V., Ivanov S. D. Spectral properties of bisbenzimidazole dyes upon interaction with DNA. Russian Journal of Bioorganic Chemistry. 1997. V. 23. No 12. P. 857866.

22. Sibirtsev V. S., Glibin E. N., Ivanov S. D. Variation of spectral properties of actinocin derivatives due to equilibrium transformations. Russian Journal of Organic Chemistry. 2000. V. 36. No 12. P. $1812-1818$.

23. Sibirtsev V. S., Garabadzhiu A. V., Ivanov S. D. Comparative study of DNA-specific dyes of the indole and benzimidazole series. Russian Journal of Bioorganic Chemistry. 2001. V. 27. No 1. P. 57-65. doi: 10.1023/A:1009535320077

24. Sibirtsev V. S., Tolmachev A. Yu., Suslov V. V., Garabadzhiu A. V., Traven' V. F. Dependence of fluorescence properties of compounds from psoralen, angelicin, and carbazole series on the character of their terminal substituents. Russian Journal of Organic Chemistry. 2003. V. 39. No 6. P. 881889. doi: 10.1023/B: RUJO. 0000003169.96393.1d

25. Sibirtsev V. S. Study of applicability of the bifunctional system "Ethidium bromide + Hoechst-33258" for DNA analysis. Biochemistry. 2005. V. 70. No 4. P. 449-457. doi: 10.1007/ s10541-005-0136-x

26. Sibirtsev V. S., Tolmachev A. Yu., Kovaleva M. V., Garabadzhiu A. V., Traven V. F. Spectral study of interactions of 4,8,4' - trimethylpsoralen and 4,4' - dimethylangelicin dyes with DNA. Biochemistry. 2005. V. 70. No 7. P. 822-832. doi: 10.1007/s10541-005-0190-4

27. Sibirtsev V. S. Fluorescent DNA probes: study of mechanisms of changes in spectral properties and features of practical application. Biochemistry. 2007. V. 72. No 8. P. 887-900. doi: 10.1134/S0006297907080111

28. Sibirtsev V. S., Naumov I. A., Kuprina E. E., Olekhnovich R. O. Use of impedance biotesting to assess the actions of pharmaceutical compounds on the growth of microorganisms. Pharmaceutical Chemistry Journal. 2016. V. 50. No 7. P. 481485. doi: 10.1007/s11094-016-1473-3 
29. Sibirtsev V. S., Olekhnovich R. O., Samuylova E. O. Assessment of integral toxicity of water resources by instrumental methods of analysis. // International Multidisciplinary Scientific GeoConference Surveying Geology and Mining Ecology Management (SGEM) Conference Proceedings. 2017. V. 17. No 61. P. 507-514. doi: $10.5593 /$ sgem 2017/61/S24.066

30. Sibirtsev V. S. Biological test methods based on fluorometric genome analysis. // Journal of Optical Technology. 2017. V. 84. No 11. P. 787-791. doi: 10.1364/JOT. 84.000787

31. Kokina M. S., Frioui M., Shamtsyan M., ets. Influence of pleurotus ostreatus beta-glucans on the growth and activity of certain lactic acid bacteria. // Scientific Study and Research: Chemistry and Chemical Engineering, Biotechnology, Food Industry. 2018. V. 19. No 4. P. 465-471.

32. Sibirtsev V. S., Uspenskaya M. V., Garabadgiu A. V., Shvets V. I. An integrated method of instrumental microbiotesting of environmental safety of various products, wastes, and territories. // Doklady Biological Sciences. 2019. V. 485. No 1. P. 59-61. doi: 10.1134/S001249661902011X

33. Сибириев В. С., Строев С. А. Оптико-электрохимическая микробиотестовая система оценки токсической безопасности нефтепродуктов. // Научно-технический вестник информационных технологий, механики и оптики. 2019. Т. 19. № 1. C. 74-81. doi: 10.17586/2226-1494-2019-19-1-74-81

34. Сибириев В. С., Маслова А. Ю. Комплексное исследование динамики жизнедеятельности Е. coli в присутствии ионов переходных металлов. // Научно-технический вестник информационных технологий, механики и оптики. 2019. Т. 19. № 2. С. 236-241. doi: 10.17586/2226-1494-2019-19-2-236-241

35. Патент РФ № 2688119. Способ определения антибиотических свойств материалов. /Сибирцев В. С., Щемелинина Т. Н., Успенская М. В., Гарабаджиу А. В.; зарег. в гос. реестре изобрет. 17.05.2019, бюлл. №14; приоритет от 12.04.2018.

36. Патент РФ № 2688328. Способ определения бактерицидных свойств веществ. /Сибирцев В. С., Успенская М. В.; зарег. в гос. реестре изобрет. 21.05.2019, бюлл. №15; приоритет от 27.06.2018.

\section{Сведения об авторах}

\section{Сибирцев Владимир Станиславович}

к. х. н., доцент Университета ИТМО, 197101, Санкт-Петербург, Кронверкский пр., 49, vs1969r@mail.ru, ORCID ID: 0000-0003-0829-5213, SPIN ID: 1707-0169,

Scopus ID: 6603964394, Researcher ID: M-3146-2014

\section{Чеканов Максим Александрович}

к. Х. н., старший научный сотрудник отдела биомедицинской химии Института молекулярной биологии и генетики Национальной академии наук Украины, 03143, Украина, г. Киев, ул. Академика Заболотного, 150, chekanov.maxx@gmail.com

\section{Наумов Игорь Александрович}

магистрант, инженер факультета пищевых биотехнологий и инженерии Университета ИТМО, 191002, Санкт-Петербург, ул. Ломоносова, 9, 89043321476@mail.ru

\section{Строев Сергей Александрович}

к. б. н., профессор, научный сотрудник

Университета Тампере, 33014, Финляндия, Тампере,

s_stroev@hotmail.com
29. Sibirtsev V. S., Olekhnovich R. O., Samuylova E. O. Assessment of integral toxicity of water resources by instrumental methods of analysis. International Multidisciplinary Scientific GeoConference Surveying Geology and Mining Ecology Management (SGEM) Conference Proceedings. 2017. V. 17. No 61. P. 507-514. doi: 10.5593/sgem2017/61/S24.066

30. Sibirtsev V. S. Biological test methods based on fluorometric genome analysis. Journal of Optical Technology. 2017. V. 84. No 11. P. 787-791. doi: 10.1364/JOT. 84.000787

31. Kokina M. S., Frioui M., Shamtsyan M., ets. Influence of pleurotus ostreatus beta-glucans on the growth and activity of certain lactic acid bacteria. Scientific Study and Research: Chemistry and Chemical Engineering, Biotechnology, Food Industry. 2018. V. 19. № 4. P. 465-471.

32. Sibirtsev V. S., Uspenskaya M. V., Garabadgiu A. V., Shvets V. I. An integrated method of instrumental microbiotesting of environmental safety of various products, wastes, and territories. Doklady Biological Sciences. 2019. V. 485. № 1. P. 5961. doi: 10.1134/S001249661902011X

33. Sibirtsev V. S., Stroev S. A. New optical-electrochemical microbiotesting system for valuation of oil products toxicosafety. Scientific and Technical Journal of Information Technologies, Mechanics and Optics. 2019. V. 19. No 1. P. 74-81. (in Russian) doi: 10.17586/2226-1494-2019-19-1-74-81

34. Sibirtsev V. S., Maslova A. Yu. Complex research of E. coli vital activity dynamics in presence of transition metal ions. // Scientific and Technical Journal of Information Technologies, Mechanics and Optics, 2019. V. 19. № 2. P. 236-241. (in Russian) doi: 10.17586/2226-1494-2019-19-2-236-241

35. RF patent No 2688119. A method for determining the antibiotic properties of materials. / Sibirtsev V. S., Schemelinina T. N., Uspenskaya M. V., Garabadzhiu A. V.; registered from 05.17.2019, bull. No 14 (in Russian)

36. RF patent No 2688328. A method for determining the bactericidal properties of substances. / Sibirtsev V. S., Uspenskaya M. V.; registered from 05.21.2019, bull. No 15 (in Russian)

\section{Information about authors}

\section{Sibirtsev Vladimir Stanislavovich}

PhD, Associate Professor of ITMO University, 197101, Russia, St. Petersburg, Kronverksky ave., 49, vs1969r@mail.ru, ORCID ID: 0000-0003-0829-5213, Scopus ID: 6603964394, Researcher ID: M-3146-2014

\section{Chekanov Maksym Aleksandrovych}

$\mathrm{PhD}$., Senior research scientist of Medicinal chemistry department of Institute of molecular biology and genetics of Ukraine national academy of sciences, 03143, Ukraine, Kyiv, Zabolotnogo str., 150, chekanov.maxx@gmail.com

\section{Naumov Igor Aleksandrovich}

Undergraduate, Engineer of the Faculty of Food Biotechnology and Engineering of ITMO University, 191002, Russia, St. Petersburg, Lomonosov str., 9, 89043321476@mail.ru

\section{Stroyev Sergey Aleksandrovich}

$\mathrm{PhD}$, Researcher of University of Tampere,

33014, Finland, Tampere,

s_stroev@hotmail.com 